\title{
LOW-LEVEL ENVIRONMENTAL LEAD EXPOSURE AND INTELLECTUAL IMPAIRMENT IN CHILDREN - THE CURRENT CONCEPTS OF RISK ASSESSMENT
}

\author{
MAREK JAKUBOWSKI \\ Nofer Institute of Occupational Medicine, Łódź, Poland \\ Department of Chemical Safety
}

\begin{abstract}
Lead is an environmental contaminant. The majority of epidemiological research on the health effects of lead has been focused on children, because they are more vulnerable to lead than adults. In children, an elevated blood lead $(\mathrm{B}-\mathrm{Pb})$ is associated with reduced Intelligence Quotient (IQ) score. This paper summarizes the current opinions on the assessment of the health risk connected with the children's environmental exposure to lead. The B-Pb level of concern of $100 \mu \mathrm{g} / \mathrm{l}$ proposed by the US Centers of Disease Control in 1991 was for a long time accepted as the guideline value. In the meantime there has been a significant worldwide decrease of $\mathrm{B}-\mathrm{Pb}$ levels in children and present geometric mean values in the European countries range from 20 to $30 \mu \mathrm{g} / \mathrm{l}$. The recent analyses of the association of intelligence test scores and B-Pb levels have revealed that the steepest declines in IQ occur at blood levels $<100 \mu \mathrm{g} / \mathrm{l}$ and that no threshold below which lead does not cause neurodevelopmental toxicity can be defended. European Food Safety Authority (EFSA) concluded in 2010, on the basis of results of Benchmark Dose (BMD) analysis, that an increase in $\mathrm{B}-\mathrm{Pb}$ of $12 \mu \mathrm{g} / \mathrm{l}\left(\mathrm{BMDL}_{01}\right)$ could decrease the IQ score by one point. It seems that this value can be used as a "unit risk" to calculate the possible decrease of IQ and, consequently, influence of the low-level exposure to lead $(<100 \mu \mathrm{g} / \mathrm{l})$ on the health and socioeconomic status of the exposed population.
\end{abstract}

Key words:

Lead, children, Risk assessment, Environmental exposure

\section{INTRODUCTION}

Lead is an environmental contaminant released into the atmosphere from natural and anthropogenic sources. Emission of lead during non-ferrous metal production and manufacturing, extensive use of lead in paints, or as additive to gasoline took place on the global scale and can be considered as one of the biggest environmental disasters of anthropogenic origin.

Lead is well-studied toxic metal, and a wide range of known biological effects depends upon the level and duration of exposure. In adults, health effects of exposure to lead can include inhibition of several enzymes involved in heme synthesis, influence on the functions of peripheral and central nervous system, increase of blood pressure, which is a significant risk factor for cardiovascular diseases. The majority of the epidemiological research on the health effects of lead has been focused on children, because they are more vulnerable to lead than adults. Children's behaviour and lifestyle (more hand-tomouth activities, being physically closer to ground level, and more time spent outdoors) result in greater intake of lead from contaminated soil or dust compared with

Received: November 8, 2010. Accepted: December 2, 2010.

Address reprint request to M. Jakubowski, Nofer Institute of Occupational Medicine, Department of Chemical Safety, św. Teresy 8, 91-348 Łódź, Poland (e-mail: majakub@imp.lodz.pl). 
adults. Also absorption of lead from gastrointestinal tract is higher in children than in adults. There is considerable evidence demonstrating that the developing brain is more vulnerable to the neurotoxicity of lead than the mature brain. In children, an elevated blood lead (B-Pb) causes concentration-dependent reduction in Intelligence Quotient (IQ) score and reduced cognitive functions up to at least seven years of age.

There is some evidence that this subsequently leads to a reduced adult grey matter volume, especially of the prefrontal cortex [1].

Therefore, childhood lead poisoning remains one of critical environmental health concerns. In spite of significant reduction of lead emission it nevertheless continues to inflict harm on many children throughout the world. According to the recently published opinion by Grandjean [2], a generation of children paid the price for us to obtain insight into lead pollution. Future risk assessment of environmental pollutants should not ignore risks of low-level toxicity in susceptible populations because convincing evidence is not available.

The aim of this paper is to review the current opinions on the assessment of the health risk connected with the children's environmental exposure to lead.

\section{ENVIRONMENTAL EXPOSURE}

Control measures have been taken to regulate lead in paint, petrol, food cans and water pipes in Europe since the 1970s. This resulted in significant reduction of emission which decreased in 24 countries in the EMEP region by more than $90 \%$ between 1990 and 2003 mainly because of restrictions on the use of leaded petrol. In Europe, in 2003, the concentrations of lead in the air mainly ranged between 5 and $15 \mathrm{ng} / \mathrm{m}^{3}$. Lead concentrations in top-soils are spatially heterogenous and vary from below $10 \mathrm{mg} / \mathrm{kg}$ up to $>70 \mathrm{mg} / \mathrm{kg}$. The median value is estimated to be $22.6 \mathrm{mg} / \mathrm{kg}$ [3].
Dietary exposure is clearly the dominating source of overall lead exposure for children, although high soil and dust intake can be a factor for children, particularly in contaminated areas. According to EFSA [1] across the Member States of European Union lead intakes with food in 1 to 14 years old children decrease with age. In one year old children P50 lower and upper bound values amounted to 1.32 and $2.54 \mu \mathrm{g} / \mathrm{kg}$ b.w. per day in and in 14 years old from 0.55 to $0.96 \mu \mathrm{g} / \mathrm{kg}$ b.w. per day. The corresponding values for P95 were 2.66 and $5.07 \mu \mathrm{g} / \mathrm{kg}$ b.w. per day and 0.83 and $1.53 \mu \mathrm{g} / \mathrm{kg}$ b.w. per day, respectively. In Germany, Wilhelm et al. [4] investigated the lead intake in children at the age of 14-83 months, inhabiting industrial and rural areas. The P50 values in three different groups were from 0.71 to $0.79 \mu \mathrm{g} / \mathrm{kg}$ b.w. per day and the $\mathrm{P} 95$ value ranged from 1.31 to $1.71 \mu \mathrm{g} / \mathrm{kg}$ b.w. per day. Much lower values of lead intake from food were published by the US EPA [5]. According to these data, the daily intake of lead by the children in the USA reached about $0.57 \mu \mathrm{g} / \mathrm{kg}$ b.w. per day in one-two year old and to 0.31 in 6 year old. A Provisional Tolerable Weekly Intake of $25 \mu \mathrm{g} / \mathrm{kg}$ b.w. has been established since ten years for all age groups by the FAO/WHO Expert Committee on Food Additives [6]. This value corresponding to the $3.57 \mu \mathrm{g} / \mathrm{kg}$ b.w./day is roughly five times higher than the current data for Europe or the U.S.

Most of the information on human exposure to, and the health effects of lead is based on $\mathrm{B}-\mathrm{Pb}$ data. Lead in blood has two main pools. The fast pool ( $\mathrm{t}_{1 / 2}$ about 1 month) is in the blood and soft tissues and the slow one ( $t_{1 / 2}$ ranging from 10 to 30 years) is mainly in the skeleton). At steadystate, $\mathrm{B}-\mathrm{Pb}$ reflects a combination of recent lead exposure and that which occurred several years previously. A major advantage of this measure is the wealth of information that can be linked to $\mathrm{B}-\mathrm{Pb}$, particularly the effects of low environmental exposure on central nervous system functions in children $[1,3]$.

There has been a significant worldwide decrease of B-Pb levels over the last two decades, which followed the 
substantial decrease of lead emission, mainly due to the elimination of lead from petrol. In Sweden, the geometric mean B-Pb concentrations decreased from about $60 \mu \mathrm{g} / \mathrm{l}$ in 1978 to about $15-18 \mu \mathrm{g} / \mathrm{l}$ in 2005 [3]. In the German Environmental Survey on Children, the $\mathrm{B}-\mathrm{Pb}$ geometric mean concentrations ranged from $19.6 \mu \mathrm{g} / \mathrm{l}$ in the $3-5$ year old group to $14.6 \mu \mathrm{g} / \mathrm{l}$ in the $12-14$ year old group. The reference value was lowered from 50 to $35 \mu \mathrm{g} / \mathrm{l}$ [7]. In the Czech Republic the median B-Pb level was $31 \mu \mathrm{g} / \mathrm{l}$ and the proposed reference level for children $55 \mu \mathrm{g} / \mathrm{l}$ [8]. In the U.S. the geometric mean $\mathrm{B}-\mathrm{Pb}$ concentration in children (6-11 year old group) was in the 1999-2000 and 2003-2004 period $15.1 \mu \mathrm{g} / \mathrm{l}$ and $12.5 \mu \mathrm{g} / \mathrm{l}$, respectively [9].

\section{HISTORY OF THE ADMISSIBLE B-PB LEVELS}

The adverse health effects associated with elevated $\mathrm{B}-\mathrm{Pb}$ levels have been widely studied. In the U.S., Centers for Disease Control (CDC) lowered the B-Pb level of concern from $600 \mu \mathrm{g} / \mathrm{l}$ in 1960 to $250 \mu \mathrm{g} / \mathrm{l}$ in 1990. In 1991, the $\mathrm{CDC}$ recommended lowering the level for individual intervention to $150 \mu \mathrm{g} / \mathrm{l}$ and implementing communitywide primary lead poisoning prevention activities in areas where many children have $\mathrm{B}-\mathrm{Pb} \geq 100 \mu \mathrm{g} / \mathrm{l}$. Some activities, such as educating parents about lead, and conducting follow-up $\mathrm{B}-\mathrm{Pb}$ monitoring were suggested for children with $\mathrm{B}-\mathrm{Pb} \geq 100 \mu \mathrm{g} / \mathrm{l}[10]$.

In 2000 the World Health Organization, Regional Office for Europe edited Air Quality Guidelines for Europe [11]. In conclusion the WHO experts recommended that efforts be made to ensure that at least $98 \%$ of an exposed population, including preschool children, have $\mathrm{B}-\mathrm{Pb}$ levels that do not exceed $100 \mu \mathrm{g} / \mathrm{l}$. In this case, the median blood lead level would not exceed $54 \mu \mathrm{g} / \mathrm{l}$.

The level of $100 \mu \mathrm{g} / \mathrm{l}$, which was originally intended to trigger community-wide prevention activities, has been misinterpreted frequently as a definitive toxicologic threshold and commonly accepted as the guideline value [10].
In 2006, in the Declaration of Brescia [12], the Scientific Committee on Neurotoxicity and Psychophysiology and the Scientific Committee on the Toxicology of Metals of the International Commission on Occupational Health proposed that for children the action level, which triggers community prevention efforts to reduce exposure sources, should be immediately reduced to a blood lead concentration of $50 \mu \mathrm{g} / \mathrm{l}$ in nations worldwide. This level was proposed as a temporary level that may need to be revised further downward in future years as new evidence accumulates on toxicity at still lower blood lead levels. Gilbert and Weiss [13] suggested that CDC should lower the blood B-Pb action level in children to $20 \mu \mathrm{g} / \mathrm{l}$.

However, a statement published in 2005 by the CDC [10] indicates that at this time there are valid reasons not to lower the level of concern of $100 \mu \mathrm{g} / \mathrm{l}$ established in 1991 including the following:

1. No one threshold for adverse effects has been demonstrated. Thus the process for establishing a lower level of concern would be arbitrary and no particular $\mathrm{B}-\mathrm{Pb}$ cutoff can be defended on the basis of existing data. In addition, establishing a lower level of concern may provide a false sense of safety about the well being of children whose B-Pb levels are below the threshold.

2. Efforts to identify and provide services to children with $\mathrm{B}-\mathrm{Pb}<100 \mu \mathrm{g} / \mathrm{l}$ may deflect needed resources from children with higher $\mathrm{B}-\mathrm{Pb}$ levels who are likely to benefit most from individual interventions.

3. Efforts to eliminate lead exposures through primary prevention have the greatest potential for success. Reducing exposures will benefit all children, regardless of their current B-Pb levels.

These conclusions, which justify the present CDC level of concern, underline very important social aspects of the problem. They also contain an important statement that establishing a lower level of concern would be arbitrary. The same approach has been recently implemented by the German Human Biomonitoring Commission [14]. This 
Commission propose Human Biomonitoring (HBM) Values, which by definition are health-based exposure limits derived from toxicological, epidemiological studies or toxicokinetic extrapolation. Two levels are defined: HBM I and HBM II. Below HBM I value, damage to health is not to be expected according to current knowledge. In 1996, the Commission set HBM I of $100 \mu \mathrm{g} / \mathrm{l}$ for lead in blood of children $\leq 12$ years and females of a reproductive age. However, in 2010 the Commission concluded that any setting of an "effect threshold" for B-Pb levels would be arbitrary and removed the former recommendation from the HBM list.

Recently, only chemical industry proposed in the Voluntary Risk Assessment Report published in 2008 [15] the No Adverse Effect Level (NOAEL) of $100 \mu \mathrm{g} / \mathrm{l}$ for effects at the level of the individual child. In addition, on a precautionary basis that guards against lead impacts upon child development that are too subtle to manifest at the level of the individual, a "societal" NOAEL of $50 \mu \mathrm{g} / \mathrm{l}$ has been put forward. It seems that at present no particular B-Pb cutoff can be defended on the basis of existing data and that another solution aiming at the risk assessment in this field should be proposed.

\section{THE QUANTITATIVE RELATIONSHIP BETWEEN CHILDREN'S PERFORMANCE ON IQ TESTS AND B-PB CONCENTRATIONS}

In 1995 IPCS [16] performed meta-analyses of the numerous prospective and cross-sectional studies focused on children. In the most studies a negative association between lead measures and IQ measures (critical effect) was found The final conclusions suggested a mean decrease in full-scale IQ of the order of 2 IQ points for a change in mean B-Pb level from 100 to $200 \mu \mathrm{g} / \mathrm{l}$.

A growing body of evidence, however, revealed that blood lead levels below $100 \mu \mathrm{g} / \mathrm{l}$ may impair children's neurobehavioral development.

Lanphear et al. [17] examined an association of intelligence test scores and blood lead concentration, especially for children who had maximal measured $\mathrm{B}-\mathrm{Pb}$ level $100 \mu \mathrm{g} / \mathrm{l}$. Data were collected from 1333 children who participated in seven international population-based longitudinal cohort studies, followed from birth or infancy until 5-7 years of age. The full- scale IQ score was the primary outcome measure. The geometric mean $\mathrm{B}-\mathrm{Pb}$ of the children peaked at $178 \mu \mathrm{g} / \mathrm{l}$ and declined to $94 \mu \mathrm{g} / \mathrm{l}$ by 5-7 years of age; $244(18 \%)$ children had a maximal B-Pb concentration < $100 \mu \mathrm{g} / \mathrm{l}$, and $103(8 \%)$ had a maximal $\mathrm{B}-\mathrm{Pb}<75 \mu \mathrm{g} / \mathrm{l}$. After adjustment for covariates, an inverse relationship between $\mathrm{B}-\mathrm{Pb}$ and $\mathrm{IQ}$ score has been found. The shape of log-linear model indicated that the steepest declines in IQ were at blood levels $<100 \mu \mathrm{g} / \mathrm{l}$ (Figure 1). The log-linear model estimated a decrement of 6.9 IQ points (95\% CI: 4.2-9.4) associated with an increase in concurrent blood lead from 24 to $300 \mu \mathrm{g} / \mathrm{l}$. The estimated IQ point decrements associated with an increase in blood lead fro m 24 to $100 \mu \mathrm{g} / \mathrm{l}, 100$ to $200 \mu \mathrm{g} / \mathrm{l}$ and 200 to $300 \mu \mathrm{g} / \mathrm{l}$ were 3.9 (95\% CI: 2.4-5.3), 1.9 (95\% CI: 1.2-2.6) and 1.1 (95\% CI: 0.7-1.5), respectively.

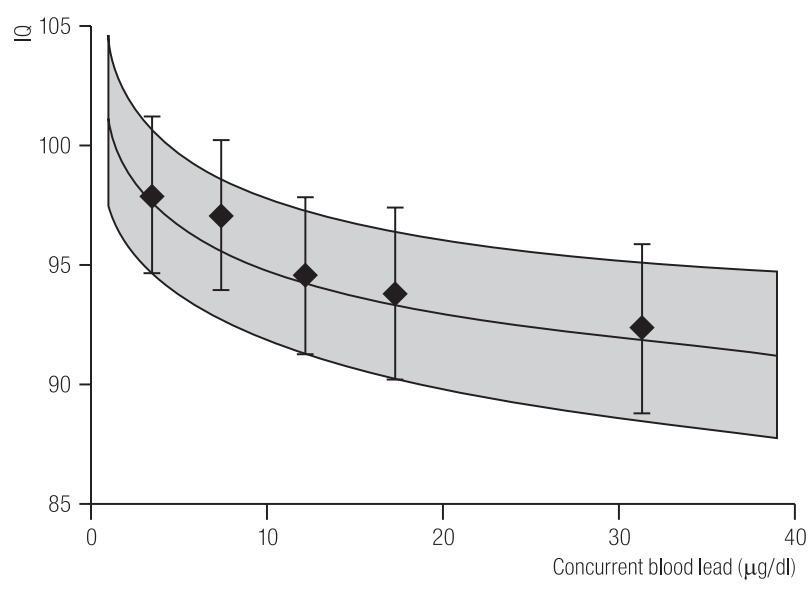

The mean IQ $(95 \% \mathrm{Cl})$ for the intervals $<5 \mu \mathrm{g} / \mathrm{dl}, 5-10 \mu \mathrm{g} / \mathrm{dl}$, $10-15 \mu \mathrm{g} / \mathrm{dl}, 15-20 \mu \mathrm{g} / \mathrm{dl}$, and $>20 \mu \mathrm{g} / \mathrm{dl}$ are shown [17]. Reproduced with permission from Environmental Health Perspectives.

Fig. 1. IQ loss versus blood lead level. Log-linear model (95\% Cls shaded) for concurrent blood lead concentration, adjusted for HOME score, maternal education, maternal IQ and birth weight. 
Miranda et al. evaluated the relation between blood lead levels in early childhood and educational achievement in early elementary school as measured by performance on end-of grade (EOG) testing [18]. The discernible impact of $\mathrm{Pb}-\mathrm{B}$ levels on EOG testing was found for early childhood blood levels as low as $20 \mu \mathrm{g} / \mathrm{l}$. A Pb-B of $50 \mu \mathrm{g} / \mathrm{l}$ was associated with the decline in EOG reading (and mathematics) scores roughly equal to $15 \%$ of the interquartile range.

Jusko et al. examined the association between $\mathrm{Pb}$ - B assessed throughout early childhood and children's IQ at 6 years of age [19]. Children were followed from 6 months to 6 years of age. At 6 years of age intelligence was assessed in 194 children using the Wechsler Preschool and Primary Scale of Intelligence-Revised. After adjustment for maternal IQ, HOME scale stores, and other potential confounders, lifetime average $\mathrm{Pb}$-B (mean: $72 \mu \mathrm{g} / \mathrm{l}$; median: $62 \mu \mathrm{g} / \mathrm{l}$ ) was inversely associated with Full-Scale IQ and Performance IQ Scores. Compared with children who had lifetime average $\mathrm{Pb}-\mathrm{B}$ concentrations $<50 \mu \mathrm{g} / \mathrm{l}$, children with lifetime average concentrations between 50 and $99 \mu \mathrm{g} / \mathrm{l}$, scored 4.9 points lower on Full-Scale IQ 9 (91.3 vs. 86.4, p = 0.03). Nonlinear modelling of the peak $\mathrm{Pb}-\mathrm{B}$ concentration revealed an inverse association $(p=0.003)$ between peak $\mathrm{Pb}-\mathrm{B}$ and FullScale IQ down to $21 \mu \mathrm{g} / \mathrm{l}$.

These findings suggested that more children may be adversely affected by environmental lead than previously estimated. Due to the general decline in lead exposure it has been critical to estimate quantitatively the exposureresponse relationship at blood levels $<100 \mu \mathrm{g} / \mathrm{l}$.

In 2010 European Food Safety Authority (EFSA) Panel on Contaminants in the Food Chain (CONTAM) published Scientific Opinion on Lead in Food [1]. The CONTAM Panel identified the decrease of (full scale) IQ as intellectual deficit in children at ages 4 and higher as the critical endpoint for neurodevelopmental effects. CONTAM Panel performed a refined Benchmark Dose (BMD) analysis of the same complete individual data from the 1333 children that had been used for the international pooled analysis performed by
Lanphear et al. [16]. The $\mathrm{BMD}_{01}$ was defined as the increase of $\mathrm{B}-\mathrm{Pb}$ level which induces loss of $1 \mathrm{IQ}$ point. The $\mathrm{BMDL}_{01}$ was defined as a lower one-sided 95\% confidence limit of the BMD. The Benchmark calculations were based on standard multiple regression models. As the dependent variable the full IQ score was used. Both $\mathrm{BMD}_{01}$ and $\mathrm{BMDL}_{01}$ were calculated using each of the four B-Pb exposure variables available: concurrent lead, peak lead, lifetime average lead and early childhood lead. Based on the dose-response analysis, the CONTAM Panel chose a BMDL $\mathrm{B}_{01}$ of $12 \mu \mathrm{g} / \mathrm{l} \mathrm{B-Pb}$ as reference point for the risk characterization of lead for assessing the risk of intellectual deficits in children as measured by the Full Scale IQ.

Similar conclusion has been reached by Carlisle et al. [20]. Based on a published meta-analysis of children's IQ scores and their B-Pb levels they found that an incremental increase in B-Pb of $10 \mu \mathrm{g} / \mathrm{l}$ could decrease the IQ score in an average school child in California by up to one point and that this benchmark value can be used for risk assessment of children's exposure.

According to the published opinions, seemingly small decrease of cognitive ability by 1 IQ point would have an impact on the socioeconomic status of the population and its productivity. Schwartz [21] related a 1 point reduction in IQ to a $4.5 \%$ increase in the risk of failure to graduate from high school. Grosse et al. [22] studied economic benefits from projected improvements in worker productivity from the reduction in children's exposure to lead in the U.S. and estimated that each IQ point raises worker productivity by 1.76 to $2.38 \%$. Therefore, a decrease of 1 IQ in children can be associated with a decrease of later productivity of about $2 \%$.

\section{CONCLUSIONS}

Despite the recent progress in reducing children exposure to lead, there is increasing recognition that chronic low-level exposure to lead can still have an impact on the 
central nervous system in children. There is no evidence of a threshold below which lead does not cause neurodevelopmental toxicity and at present no particular $\mathrm{B}-\mathrm{Pb}$ cutoff can be defended. According to CDC [10], establishing a level of concern lower than $100 \mu \mathrm{g} / \mathrm{l}$ may provide a false sense of safety about the well being of children whose $\mathrm{B}-\mathrm{Pb}$ levels are below this value.

Therefore, it seems that, as in the case of other substances which are lacking the well defined threshold of toxic effects, risk assessment can be performed on the basis of a kind of "unit risk". In this case the $\mathrm{BMDL}_{01}$ of $12 \mu \mathrm{g} / \mathrm{l} \mathrm{B-Pb}$, proposed by EFSA [1] can be used as an unit risk to calculate the possible decrease of IQ and consequently influence of the low-level exposure to lead on the health and socioeconomic status of the exposed population.

\section{ACKNOWLEDGEMENTS}

This paper was supported by the European Union 7th Framework Integrated Project COPHES (grant agreement No 244234).

\section{REFERENCES}

1. European Food Safety Authority (EFSA) Panel on Contaminants in the Food Chain (CONTAM). Scientific Opinion on Lead in Food. EFSA J 2010;8:1570.

2. Grandjean P. Even low-dose lead exposure is hazardous. Lancet 2010;376:855-6.

3. World Health Organization (WHO). Health risks of heavy metals from long-range transboundary air pollution. Joint WHO/ Convention Task Force on the Health Aspects of Air Pollution. Copenhagen: WHO; 2007.

4. Wilhelm M, Wittsieppe J, Schrey P, Hilbig A, Kersting M. Consumption of homegrown products does not increase dietary intake of arsenic, cadmium, lead, and mercury by young children living in the industrialized area of Germany. Sci Total Environ 2005;343:61-70.
5. United States Environmental Protection Agency (US EPA). Guidance Manual for the Integrated Exposure Uptake Biokinetic Model for Lead in Children. Overview of changes From IEUBKwin version 1 build 2646 to IEUBKwin version 1.1. US EPA; 2009.

6. JEFCA. Safety evaluation of certain food additives and contaminants. Fifty-third Meeting of the Joint FAO/WHO Expert Committee on Food Addditives. WHO Food Additives Series 44. Geneva: World Health Organization; 2000.

7. Schultz Ch, Angerer J, Ewers U, Heudorf U, Wilhelm M. Revised and new reference values for environmental pollutants in urine or blood of children in Germany from the German Environmental Survey on Children 2003-2006 (GerES IV). Int J Hyg Environ Health 2009;212:637-47.

8. Batariova A, Spevackova V, Benes B, Cejchanova M, Smid J, Cerna M. Blood and urine levels of $\mathrm{Pb}, \mathrm{Cd}$ and $\mathrm{Hg}$ in the general population of the Czech Republic and proposed reference values. Int J Hyg Environ Health 2006;209:359-66.

9. Centers for Disease Control and Prevention (CDC). National report on Human Exposure to Environmental Chemicals. Atlanta: CDC; 2010.

10. Centers for Disease Control and Prevention (CDC). Preventing Lead Poisoning in Young Children. Atlanta: CDC; 2005.

11. World Health Organization (WHO). Air Quality Guidelines for Europe. Second Edition. WHO Regional Publications, European Series, No 91. Copenhagen: WHO; 2000.

12. Landrigan P, Nordberg M, Lucchini R, Nordberg G, Grandjean $\mathrm{P}$, Iregren $\mathrm{A}$, et al. The declaration of Brescia on prevention of the neurotoxicity of metals. Am J Ind Med 2006;50:709-11.

13. Gilbert SG, Weiss B. A rationale for lowering the blood lead action level from 10 to $2 \mu \mathrm{g} / \mathrm{dl}$. Neurotoxicology 2006;27:693-01.

14. Wilhelm M, Heinzow B, Angerer J, Schulz C. Reassessment of critical lead effects by the German Human Biomonitoring Commission results in suspension of the human biomonitoring values (HBM I and HBM II) for lead in blood of children and adults. Int J Hyg Environ Health 2010;213(4):265-269. DOI10.1016/J.jiheh.2010.04.002. 
15. ILZRO and EBRC Consulting. Voluntary risk assessment report on lead and some inorganic lead compounds [final draft]. March 2008.

16. World Health Organization (WHO). IPCS Environmental Health Criteria 165. Inorganic lead. Geneva: WHO; 1995.

17. Lanphear BP, Hornung R, Khoury J, Yolton K, Baghurst P, Bellinger DC, et al. Low-level environmental lead exposure and children's intellectual function: An international pooled analysis. Environ Health Persp 2005;113:894-9.

18. Mirana ML, Kim D, Galeano MA, Paul CJ, Hull AP, Morgan SP. The relationship between early blood lead levels and performance on end-of-grade tests. Environ Health Persp 2007;115:1242-7.
19. Jusko TA, Henderson CR, Lanphear BP, Cory-Slechta DA, Parsons PJ, Canfield RL. Blood lead concentrations $<10 \mu \mathrm{g} / \mathrm{dl}$ and child intelligence at 6 years of age. Environ Health Persp 2008;116:243-8.

20. Carlisle JC, Dowling KC, Siegel DM, Alexeeff V. A blood lead benchmark for assessing risk from childhood lead exposure. J Environ Sci Health Part A 2009;44(12):1200-8.

21. Schwartz J. Societal benefits of reducing lead exposure. Environ Res 1994;66(1):105-24.

22. Grosse SD, Matte TD, Schwartz J, Jackson RJ. Economic gains resulting from the reduction in children's exposure to lead in the United States. Environ Health Persp 2002;110(6): 563-9.

This work is available in Open Access model and licensed under a Creative Commons Attribution-NonCommercial 3.0 Poland License - http://creativecommons.org/ licenses/by-nc/3.0/pl/deed.en. 